\title{
Graphene Platelets as Morphology Tailoring Additive in Carbon Nanotube Transparent and Flexible Electrodes for Heating Applications
}

\author{
Grzegorz Wroblewski, ${ }^{1}$ Konrad Kielbasinski, ${ }^{2}$ Tomasz Stapinski, ${ }^{3}$ \\ Janusz Jaglarz, ${ }^{4}$ Konstanty Marszalek, ${ }^{3}$ Barbara Swatowska, ${ }^{3}$ \\ Lucja Dybowska-Sarapuk, ${ }^{2}$ and Malgorzata Jakubowska ${ }^{1,2}$ \\ ${ }^{1}$ Institute of Metrology and Biomedical Engineering, Warsaw University of Technology, Andrzeja Boboli 8, 02-525 Warsaw, Poland \\ ${ }^{2}$ Institute of Electronic Materials Technology, Wolczynska 133, 01-919 Warsaw, Poland \\ ${ }^{3}$ AGH University of Science and Technology, Mickiewicza 30, 30-059 Krakow, Poland \\ ${ }^{4}$ Institute of Physics, Cracow University of Technology, Podchorazych 1, 30-084 Krakow, Poland
}

Correspondence should be addressed to Grzegorz Wroblewski; g.wroblewski@mchtr.pw.edu.pl

Received 5 February 2015; Accepted 4 March 2015

Academic Editor: Sukjoon Hong

Copyright (C) 2015 Grzegorz Wroblewski et al. This is an open access article distributed under the Creative Commons Attribution License, which permits unrestricted use, distribution, and reproduction in any medium, provided the original work is properly cited.

\begin{abstract}
Flexible and transparent electrodes were fabricated with spray coating technique from paints based on multiwalled carbon nanotubes with the addition of graphene platelets. The work presents the influence of graphene platelets on the paints rheology and layers morphology, which has a strong connection to the electrooptical parameters of the electrodes. The paints rheology affects the atomization during spray coating and later the leveling of the coating on the substrate. Both technological aspects shape the morphology of the electrode and the distribution of nanoparticles in the coating. All these factors influence the sheet resistance and roughness, which is linked to the optical transmission and absorbance. In our research the electrode was applied as a transparent and elastic heating element with $68 \%$ optical transmission at $550 \mathrm{~nm}$ wavelength and $8.4 \mathrm{k} \Omega / \square$ sheet resistance. The elastic heating element was tested with a thermal camera at the 3 diverse supply voltages $-20,30$, and 60 VDC. The test successfully confirmed and supported our proposed uses of elaborated electrodes.
\end{abstract}

\section{Introduction}

Spray coating is an excellent cost-effective method of fabrication particularly for large areas of dielectric [1], semiconducting [2-4], and conductive coatings [5, 6]. Thanks to the relatively small thickness of the layers this method can be used to produce transparent electrodes for optoelectronic applications such as electroluminescent displays $[5,7]$. This method is especially interesting since it is vacuum-free and does not require any restricted technological environment. Moreover the layers deposition can be conducted in low temperatures and on nonflat substrates; thus spray coating can be used for the fabrication of flexible electronic elements.

Carbon nanomaterials are widely used as functional phase in pastes and inks elaborated for printed electronics
[8-11], the fabrication of sensors [12-16], electrodes in displays [17], antennas [18,19], supercapacitors [20-22], and dyesensitized solar cells $[23,24]$. They make it possible to achieve the mechanical properties that are unattainable for metal oxides such as ITO $[25,26]$.

In this work two kinds of carbon nanomaterials were used as functional materials, multiwalled carbon nanotubes (MWCNT) and graphene platelets (GNP). Since they have great electrical properties [27], they can be used for transparent layers fabrication and they also exhibit extraordinary mechanical strength [28, 29].

Both multiwalled carbon nanotubes and graphene platelets are materials which are transparent and good electrical conductors; thus it may be supposed that the addition of graphene platelets could increase the optical 


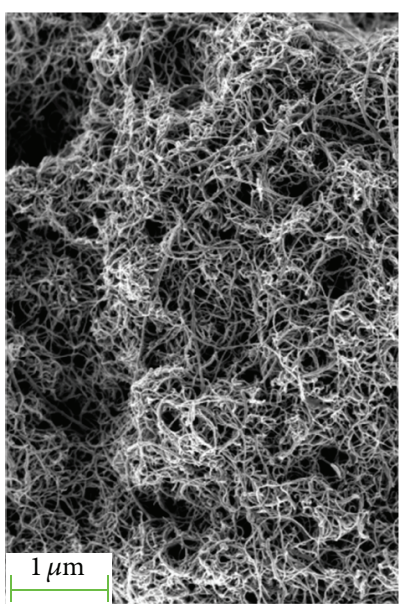

(a)

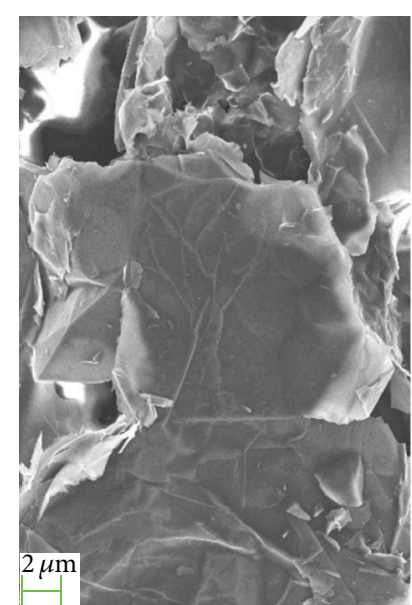

(b)

FIGURE 1: SEM pictures of (a) multiwalled carbon nanotubes and (b) graphene platelets.

transmission, while decreasing the sheet resistance of carbon nanotube electrodes. In fact, as it was shown in our previous results [30] spray coated pure GNP layers exhibit much worse electrooptical properties than pure MWCNT layers when applied as transparent electrodes. This may be related to the probability of being able to create connections between the nanoparticles which for wire-like structures seems to be higher than for those with platelet geometry. This paper presents a novel approach to the usage of graphene platelets as morphology tailoring additives. Different to the use of graphene oxide (GO) [31] our approach does not require any additional thermal [32] or chemical reduction [33] of GO to achieve suitable electrical properties. GO without the reduction is a poor electrical conductor [34] and is usually used to attach the other functional nanoparticles thanks to its large surface area functional groups [35]. The GO reduction can damage the flexible polyester (PET) substrate and is inconvenient in processing while large area electrodes are fabricated. Our results showed that small amounts of graphene platelets influence the arrangement of carbon nanotubes on the substrate which is beneficial for the electrooptical parameters of prepared electrodes. We think that the morphology tailoring of MWCNT layers via GNP addition can be an interesting alternative for the conductivity improvement by chemical processing like nitric acid treatment [36], especially where flexible or chemically sensitive substrates are used. The application test showed that elaborated material can be successfully used for transparent and flexible heating elements.

\section{Materials and Preparation}

Spray coating paints were based on carbon nanomaterials such as multiwalled carbon nanotubes (MWCNT) and graphene platelets (GNP), which were suspended in diethylene glycol monobutyl ether acetate (DBAC).

Carbon materials were purchased from Graphene Laboratories Inc. and DBAC solvent was from Sigma Aldrich.
TABLE 1: MWCNT and GNP mixed paint compositions (in relation to total mass of the paint).

\begin{tabular}{lccc}
\hline Paint name & MWCNT, wt $\%$ & GNP, wt $\%$ & DBAC solvent, wt\% \\
\hline MIX1 & 0.100 & 0 & 99.900 \\
MIX2 & 0.099 & 0.001 & 99.900 \\
MIX3 & 0.100 & 0.100 & 99.800 \\
\hline
\end{tabular}

MWCNT were synthesized by catalytic chemical vapour deposition and GNP were obtained in graphene oxide reduction. Multiwalled carbon nanotubes had length between 10 and $50 \mu \mathrm{m}$ and diameter between 10 and $15 \mathrm{~nm}$. Graphene nanoplatelets had $10 \mathrm{~nm}$ average thickness and platelet size between 2 and $25 \mu \mathrm{m}$. Scanning electron microscopy (SEM) pictures are shown on Figure 1(a) for MWCNT and Figure 1(b) for GNP.

Three MWCNT paints with addition of $0 \mathrm{wt} \%, 1 \mathrm{wt} \%$, and $100 \mathrm{wt} \%$ GNP in relation to MWCNT weight were prepared, as listed in Table 1. Firstly all paints were sonicated with higher energy for short time (for 30s) in the ultrasonic homogenizer Sonics VCX 750 to tear the bigger agglomerates than in lower energy in the ultrasonic bath (for $30 \mathrm{~min}$ ) to pull apart smaller ones, since prolonged sonication in high energy can damage carbon nanomaterials [37]. Homogenization of paints provides better paint performance which brings higher uniformity of coatings. Higher uniformity of electrodes is beneficial since the sheet resistance and light absorption are smaller.

To realize the suitable electrical connection between carbon layers and power cables necessary for the application test, silver contacts using L-121 commercial conductive ink from ITME were screen printed (AMI Presco 242) onto $125 \mu \mathrm{m}$ polyester (PET) foil substrate.

Carbon layers deposition was performed onto the PET substrate using specially developed spray coating equipment with an ultrafine nozzle spray gun mounted on a high speed plotter and supplied with an oil-free compressed air 


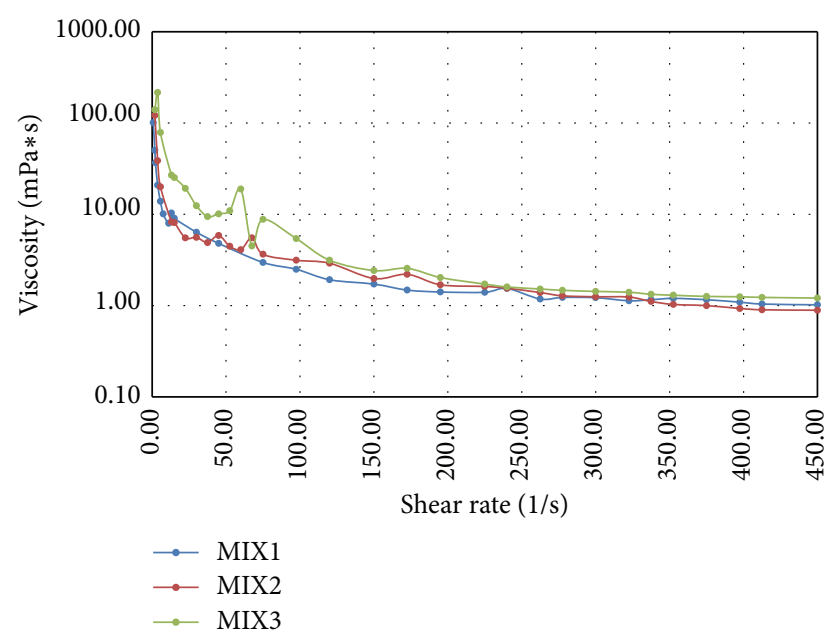

FIgURE 2: The influence of GNP addition on the paint viscosity.

system. The nozzle diameter was $450 \mu \mathrm{m}$, the air pressure was $0.3 \mathrm{MPa}$, the speed of the plotter was $300 \mathrm{~mm} / \mathrm{s}$, and the distance between the spray gun and the substrate was $120 \mathrm{~mm}$. After each layer deposition samples were dried under $150 \mathrm{~W}$ halogen lamp for 10 seconds from $120 \mathrm{~mm}$ distance. Each sample was coated with 60 layers. Eventually coatings were cured in a chamber dryer in $120^{\circ} \mathrm{C}$ for $30 \mathrm{~min}$ to evaporate the solvent.

\section{Results and Discussion}

Firstly the viscosity of prepared spray coating paints was measured by Well-Brookfield cone/plate method with Brookfield DV2T rheometer. Figure 2 shows the influence of GNP addition on the paint viscosity in function of the sheer rate.

All measured paints exhibited pseudoplastic properties. Under increase of the shear rate the viscosity decreased from $100 \mathrm{mPa} * \mathrm{~s}$ down to $1 \mathrm{mPa} * \mathrm{~s}$, which is near to the viscosity of water. Low viscosity under high shear rate enables efficient spray coating, while high viscosity at low shear rate protects the deposited wet layer from flowing down, if the a surface is inclined. The highest viscosity was observed for the paint MIX3 with the highest amount of GNP. The lowest viscosity in the range of shear rates grater then $350 \mathrm{~s}^{-1}$ (region where the atomisation occurs) was measured for the paint MIX2 with slight addition of GNP. The rheology of paints can have an influence on the layers morphology, since it is affecting the spray coating process in context of the liquid atomisation [38], when the viscosity is lower than the atomisation efficiency is higher.

The morphology of investigated samples was observed with the scanning electron microscope. Pictures of layers made with paints MIX1, MIX2, and MIX3 are presented in Figures 3(a), 3(b), and 3(c), respectively.

We can see from the SEM pictures that when graphene nanoplatelets are added, the agglomeration of carbon nanotubes is reduced and the substrate is more homogenously coated, which is beneficial for the optical transmittance of layers. It seems that MWCNT are stretched by the GNP
TABLE 2: MWCNT and GNP paints optical transmittance and sheet resistance measurements.

\begin{tabular}{lccc}
\hline Paint name & $\begin{array}{c}\text { Sheet resistance } \\
{[\mathrm{k} \Omega / \square]}\end{array}$ & $\begin{array}{c}\text { Optical } \\
\text { transmittance at } \\
\lambda=550 \mathrm{~nm}[\%]\end{array}$ & $\begin{array}{c}\text { Figure of } \\
\text { merit } \\
T^{10} / R_{s}\left[\Omega^{-1}\right]\end{array}$ \\
\hline MIX1 & 7.2 & 63 & $1.37 E+14$ \\
MIX2 & 8.4 & 68 & $2.52 \mathrm{E}+14$ \\
MIX3 & 8.7 & 60 & $6.95 E+13$ \\
\hline
\end{tabular}

TABLE 3: Average height and surface roughness " $R_{A}$ " measurements.

\begin{tabular}{lcc}
\hline Layer material & $R_{A}, \mu \mathrm{m}$ & Average height, $\mu \mathrm{m}$ \\
\hline MIX1 & 0.62 & 0.51 \\
MIX2 & 0.60 & 0.54 \\
MIX3 & 0.79 & 0.52 \\
\hline
\end{tabular}

along the substrate surface, which can be seen from higher magnitude SEM picture presented on the Figure 3(d).

Optical measurements were performed in the range from 200 to $2500 \mathrm{~nm}$ by means of PERKIN ELMER Lambda 900 spectrophotometer. The sheet resistance was measured with for point method (with Keithley 2001 multimeter) and the results are shown in Table 3 with the combination of optical transmittance results for $\lambda=550 \mathrm{~nm}$. To compare the main electrooptical properties of electrodes figure of merit proposed by Haacke [39] was used:

$$
\Phi_{\mathrm{TC}}=\frac{T^{10}}{R_{s}},
$$

where $T$ is the optical transmittance and $R_{s}$ is the sheet resistance of the transparent conductor (MWCNT and GNP paints optical transmittance and sheet resistance measurements are shown in Table 2).

In Figures 4(a) and 4(b) optical total transmittance $T_{\text {tot }}$ and diffusive transmittance $T_{\text {dif }}$ are presented for MIX1, MIX2, and MIX3. Generally optical properties are correlated with carbon nanomaterials properties $[40,41]$. The highest values of optical transmission were obtained for samples made from MIX2 paint with the addition of $0.001 \mathrm{wt} \%$ GNP. Optical transmission is significantly higher for samples consisting of pure carbon nanotubes MIX1 than these obtained from MIX3 paints with addition of $0.1 \mathrm{wt} \%$ GNP.

The result shows that a small amount of GNP in paints allows depositing layers with higher transmittance and lower reflectance. The higher amount of GNP in paints causes the reduction of optical transmittance since GNP in pure form are exhibiting lower transmission values than carbon nanotubes (CNT) [42]. Diffusive transmittance in visible range is lower for MIX2 than for MIX1 and MIX3. The highest diffusive transmittance was observed for samples fabricated from MIX3 paint with addition of $0.1 \mathrm{wt} \%$ GNP. In the near infrared region (NIR) we observed inverse trend in spectra for MIX1 and MIX3. The diffusive transmittance is the measure of the inhomogeneity of the material. It means that the higher optical scattering is due to higher bulk material inhomogeneity. Best results as regards 


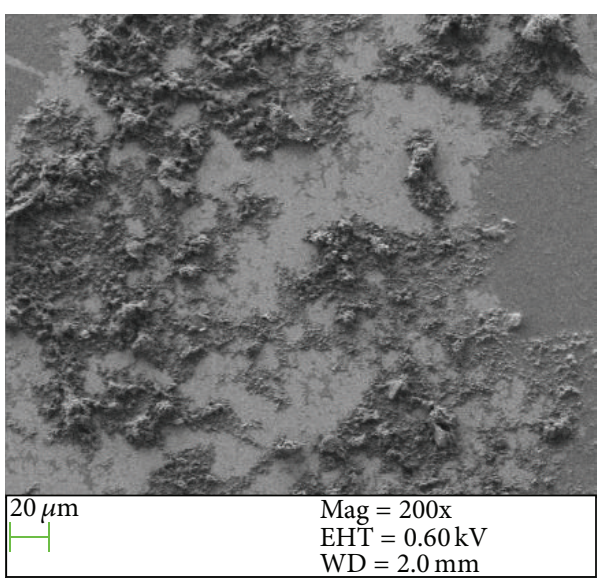

(a)

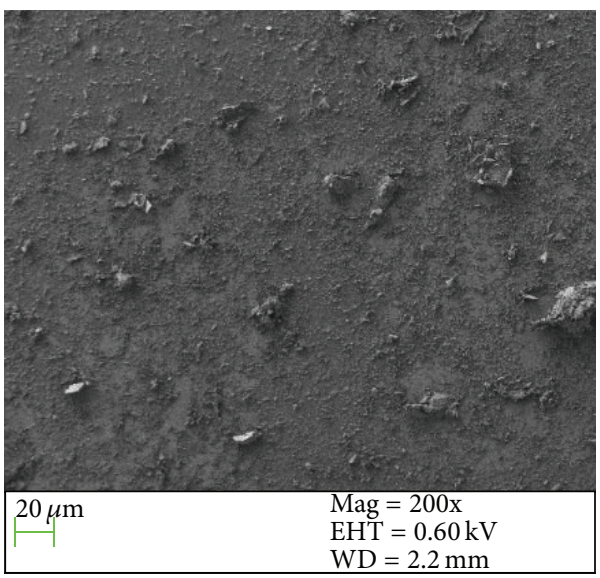

(c)

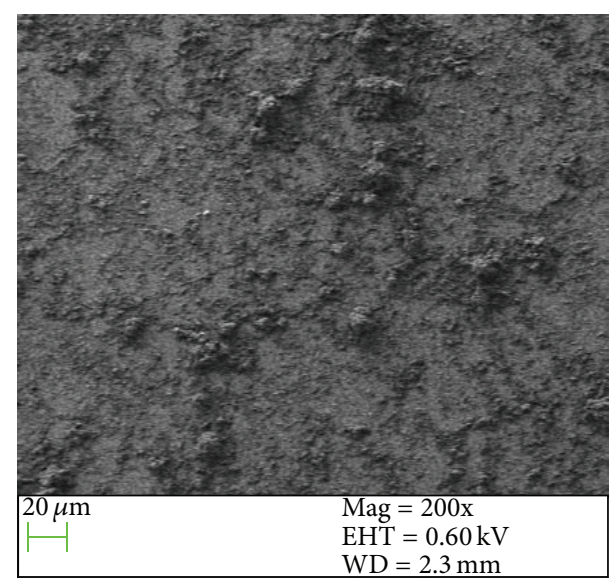

(b)

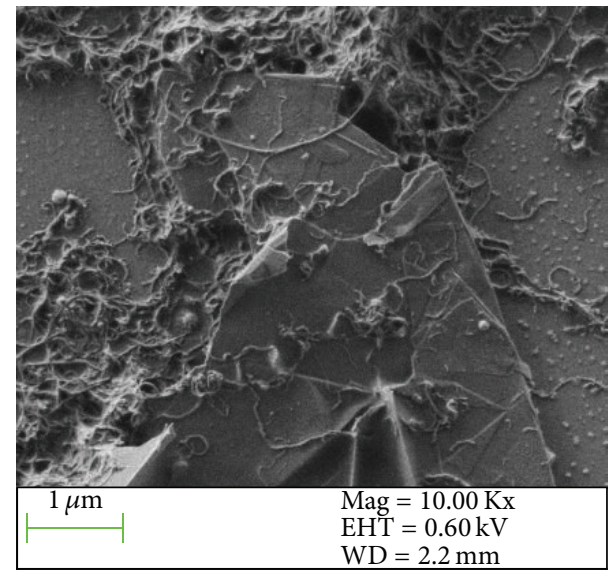

(d)

FIGURE 3: SEM pictures of (a) layer made with MIX1 paint, (b) layer made with MIX2 paint, (c) layer made with MIX3, and (d) layer made with MIX2 paint with higher magnitude to illustrate the graphene platelet in carbon nanotubes surrounding.

the optical transmittance were obtained for samples made with carbon nanotube paint MIX2 with $0.001 \mathrm{wt} \%$ addition of GNP. Results of optical total transmission $T_{\text {tot }}$ and diffusive transmission $T_{\text {dif }}$ for investigated samples were used for the determination of specular transmittance $T_{\text {spec }}$, which is calculated as the difference between total and diffusive transmission and presented in Figure 4(c). The results from optical measurements show that the higher amount of graphene platelets in the layer affects in stronger absorption of the transparent electrode.

To investigate the main surface properties of transparent electrodes, the fraction of $3 \times 0.15 \mathrm{~mm}$ of surface was scanned with the Veeco Dektak 150 3D profilometer. The surface roughness " $R_{A}$ " and average height were measured and listed in Table 3.

Average height for all measured samples was quite similar and within $0.51-0.54 \mu \mathrm{m}$. The MIX3 sample with higher amount of GNP had higher surface roughness $0.79 \mu \mathrm{m}$ compared to samples MIX2 with lower amount of GNP and MIX1 without GNP $(0.60 \mu \mathrm{m}$ and $0.62 \mu \mathrm{m}$, resp.). Surface roughness may have an influence on diffusive transmission since higher surface area can cause stronger scattering as can be seen in Figure 6. If we correlate the values of roughness parameters $R_{A}$ with the values of diffusive transmittance (measured in the range from 300 to $750 \mathrm{~nm}$ ), it can be observed that the diffusive transmission is stronger when the roughness is higher.

Since the aim of the work is related to the transparent and flexible electrodes, samples were also submitted under 150000 bending cycles, to examine their mechanical stability in the context of sheet resistance. The measurement results are shown in Figure 4(d).

For all samples a small decrease of sheet resistance was observed: $0.4 \%$ for MIX1, $0.1 \%$ for MIX2, and $0.8 \%$ for MIX3. Cyclic bending tests of electrodes showed their stability even after 150000 bending cycles which is exhibiting their application potential in flexible devices.

Eventually application test as transparent elastic heating element was performed. For the realization of this task paint MIX2 was chosen as the one which lets achieving layers with the best electrooptical parameters. The sheet resistance and optical transmission for $\lambda=550 \mathrm{~nm}$ of transparent electrode were measured after the deposition of 1-8, 15, 30, 50, 60, and 100 layers and results are shown in Figure 5(a). 


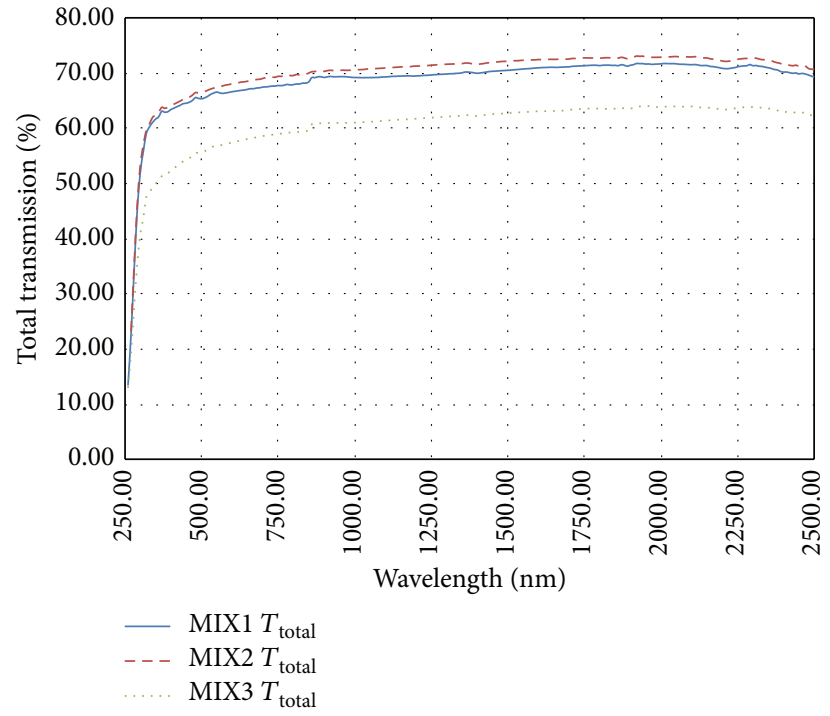

(a)

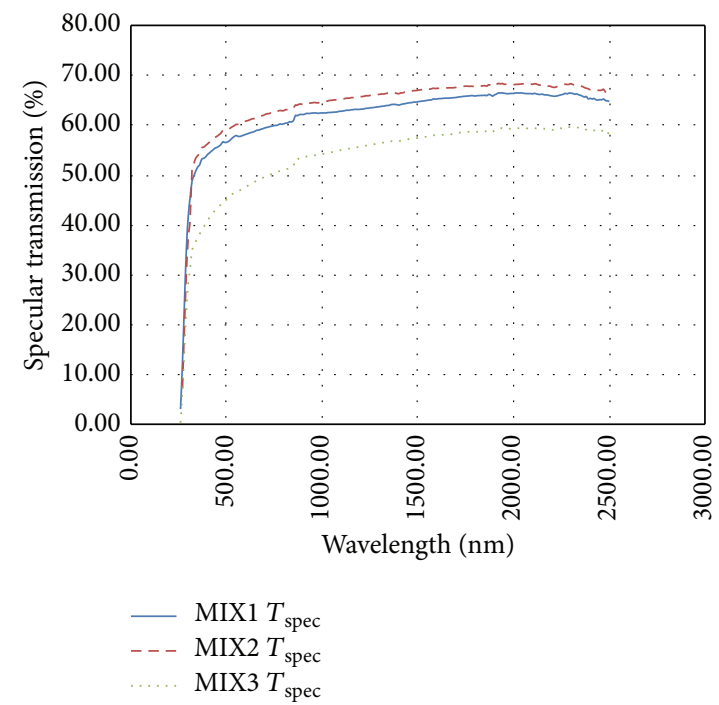

(c)



(b)

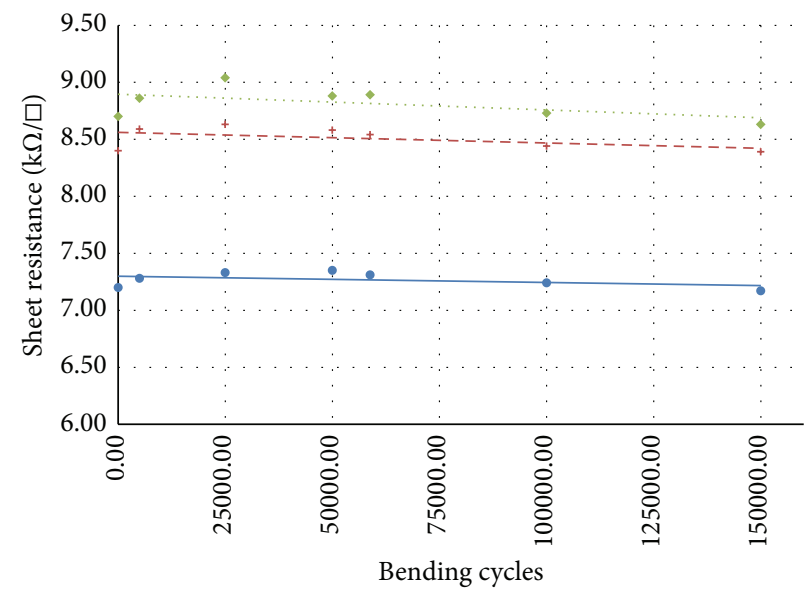

- MIX1

+ MIX2

- MIX3

(d)

Figure 4: (a) Optical total transmittance of electrodes, (b) optical diffusive transmittance of electrodes, (c) optical specular transmittance of electrodes, and (d) sheet resistance of electrodes after several bending cycles.

The best electrooptical parameters were observed for 60 layers of paint MIX2; thus the heating element was made from transparent electrode with sheet resistance $8.4 \mathrm{k} \Omega / \square$ and $68 \%$ optical transmission for $\lambda=550$. The heating element picture is shown in Figure 5(b).

Fabricated heating element was measured with the thermal camera (Vigocam V60) under several DC supplying voltages. Figures 6(a), 6(b), and 6(c) show the measurements results for $20 \mathrm{~V}, 30 \mathrm{~V}$, and $60 \mathrm{~V}$ supplying voltages, respectively, translating to Joule's heat flux of 12,27 , and $108 \mathrm{~mW} / \mathrm{cm}^{2}$ adequately. The highest temperature observed for $20 \mathrm{~V}$ was $30.54^{\circ} \mathrm{C}$, for $30 \mathrm{~V}$ was $33.22^{\circ} \mathrm{C}$, and for $60 \mathrm{~V}$ was $40.45^{\circ} \mathrm{C}$. The differences between the coldest and hottest point of the heating surface for 20,30 , and 60 VDC supplying voltage were $1.63^{\circ} \mathrm{C}, 2.53^{\circ} \mathrm{C}$, and $8.95^{\circ} \mathrm{C}$, respectively. Measurements were performed at $25^{\circ} \mathrm{C}$ ambient temperature. Results show that the homogeneity of heat emission from the surface of transparent and flexible electrodes was the highest for the lowest supplying voltage, that is, 20 VDC.

\section{Conclusions}

All investigated layers were optically transparent and conductive. SEM and roughness measurements showed that layers made with the MIX2 paint with $1 \mathrm{wt} \%$ addition of GNP were the most homogenous. Paint MIX2 allowed fabricating the transparent electrodes with the highest ratio of optical transmittance to the sheet resistance which was observed in juxtaposition of electrooptical measurements. The work presented in this paper showed that the small addition of graphene 


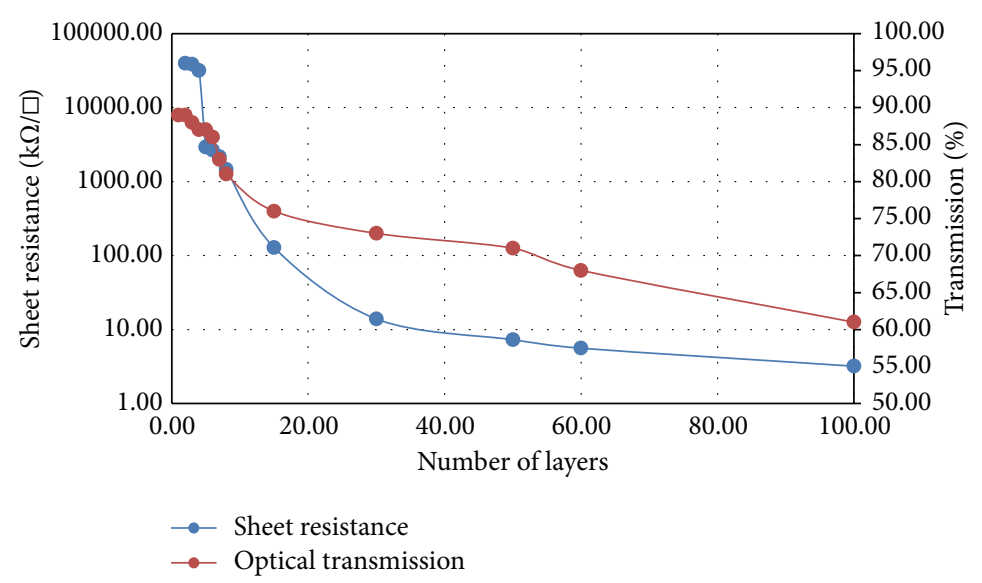

(a)

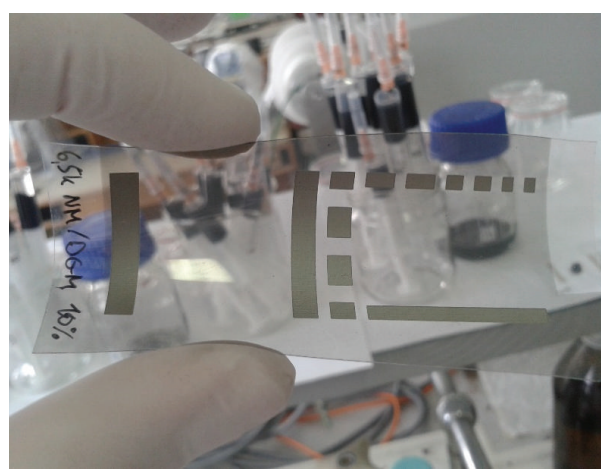

(b)

FIGURE 5: (a) Sheet resistance and optical transmission (for $\lambda=550 \mathrm{~nm}$ ) relationship with number of layers; (b) flexible and transparent heating element made with spray coated MIX2 paint.

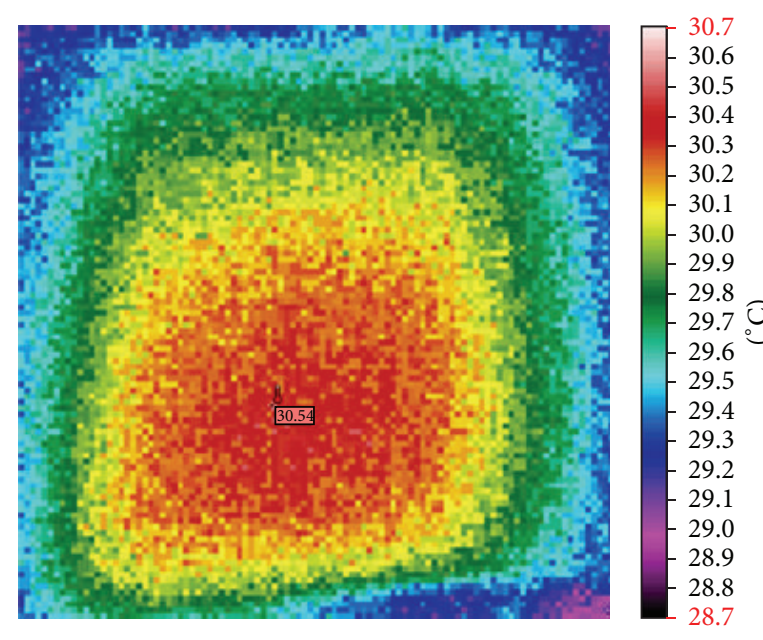

(a)

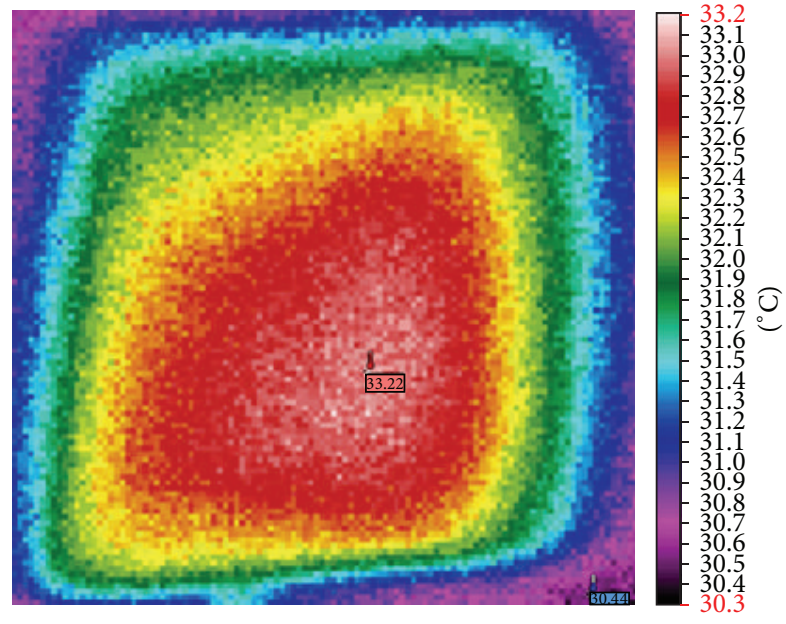

(b)

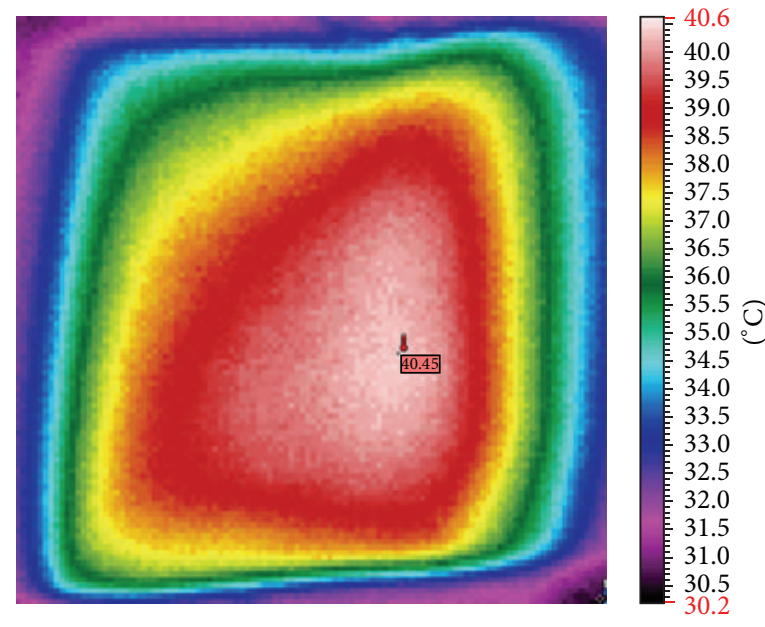

(c)

FIGURE 6: Thermogram of heating element supplied with (a) $20 \mathrm{VDC}$, highest temperature point $30.54^{\circ} \mathrm{C}$, (b) $30 \mathrm{VDC}$, highest temperature point $33.22^{\circ} \mathrm{C}$, and (c) $60 \mathrm{VDC}$, highest temperature point $40.45^{\circ} \mathrm{C}$. 
platelets ( $1 \mathrm{wt} \%$ GNP in relation to MWCNT weight) may be beneficial for the homogeneity of spray coated layers by the rheology and morphology tailoring without the effect on the sheet resistance, which is usually observed when polymers or surfactants are added. Values of roughness parameters $R_{A}$ were correlated with the values of diffusive transmittance, measured in the range from 300 to $750 \mathrm{~nm}$. We observed that the increase of roughness of the electrode corresponds with its stronger diffusive transmittance; thus higher amount of GNP was adverse. All investigated layers exhibited stable electrooptical parameters even after 150000 bending cycles which shows that carbon nanoparticle coatings are promising materials in flexible applications like transparent heaters for wearable electronics which was supported by a successful application test.

\section{Conflict of Interests}

The authors declare that there is no conflict of interests regarding the publication of this paper.

\section{Acknowledgment}

This work was supported by the Polish National Centre for Research and Development through GRAF-TECH/07 Project no. 513L 11420907000.

\section{References}

[1] D. Nithyaprakash, J. Chandrasekaran, B. Punithaveni, and L. Sasikumar, "The study of optical, dielectric and optoelectronic properties of dodecylbenzene sulfonic acid doped polyaniline," Optik-International Journal for Light and Electron Optics, vol. 125, no. 18, pp. 5343-5347, 2014.

[2] H.-W. Hsu and C.-L. Liu, "Spray-coating semiconducting conjugated polymers for organic thin film transistor applications," RSC Advances, vol. 4, no. 57, pp. 30145-30149, 2014.

[3] M. Dutter, K. Davis, R. Spelman, J. Groetsema, K. Hutchison, and S. K. Holland, "Low-cost thin-film deposition apparatus for solar applications," in Proceedings of the Systems and Information Engineering Design Symposium (SIEDS '14), pp. 135-140, Charlottesville, Va, USA, April 2014.

[4] H.-M. So, J. W. Sim, J. Kwon, J. Yun, S. Baik, and W. S. Chang, "Carbon nanotube based pressure sensor for flexible electronics," Materials Research Bulletin, vol. 48, no. 12, pp. 5036-5039, 2013.

[5] M. Słoma, G. Wróblewski, D. Janczak, and M. Jakubowska, "Transparent electrodes with nanotubes and graphene for printed optoelectronic applications," Journal of Nanomaterials, vol. 2014, Article ID 143094, 7 pages, 2014.

[6] Y. Zheng, S. Li, W. Shi, and J. Yu, "Spray-coated nanoscale conductive patterns based on in situ sintered silver nanoparticle inks," Nanoscale Research Letters, vol. 9, no. 1, article 145, 7 pages, 2014.

[7] M. Sloma, D. Janczak, G. Wroblewski, A. Mlozniak, and M. Jakubowska, "Electroluminescent structures printed on paper and textile elastic substrates," Circuit World, vol. 40, no. 1, pp. 13-16, 2014.

[8] T. J. Vink, M. Gillies, J. C. Kriege, and H. W. J. J. Van de Laar, "Enhanced field emission from printed carbon nanotubes by mechanical surface modification," Applied Physics Letters, vol. 83, no. 17, pp. 3552-3554, 2003.

[9] W.-J. Guan, Y. Li, Y.-Q. Chen, X.-B. Zhang, and G.-Q. Hu, "Glucose biosensor based on multi-wall carbon nanotubes and screen printed carbon electrodes," Biosensors and Bioelectronics, vol. 21, no. 3, pp. 508-512, 2005.

[10] M. Jakubowska, M. Słoma, and A. Młoniak, "Printed transparent electrodes containing carbon nanotubes for elastic circuits applications with enhanced electrical durability under severe conditions," Materials Science and Engineering: B, vol. 176, no. 4, pp. 358-362, 2011.

[11] G. Wróblewskia, M. Słomaa, D. Janczak, A. Młozniakb, and M. Jakubowska, "Influence of carbon nanoparticles morphology on physical properties of polymer composites," Acta Physica Polonica A, vol. 125, no. 4, pp. 861-863, 2014.

[12] J.-W. Han, B. Kim, J. Li, and M. Meyyappan, "A carbon nanotube based ammonia sensor on cotton textile," Applied Physics Letters, vol. 102, no. 19, Article ID 193104, 2013.

[13] J. K. Abraham, B. Philip, A. Witchurch, V. K. Varadan, and C. Channa Reddy, "A compact wireless gas sensor using a carbon nanotube/PMMA thin film chemiresistor," Smart Materials and Structures, vol. 13, no. 5, p. 1045, 2004.

[14] V. Dua, S. P. Surwade, S. Ammu et al., "All-organic vapor sensor using inkjet-printed reduced graphene oxide," Angewandte Chemie, vol. 49, no. 12, pp. 2154-2157, 2010.

[15] X. Yu, R. Rajamani, K. A. Stelson, and T. Cui, "Carbon nanotube-based transparent thin film acoustic actuators and sensors," Sensors and Actuators A: Physical, vol. 132, no. 2, pp. 626-631, 2006.

[16] S. Jampasa, W. Wonsawat, N. Rodthongkum et al., "Electrochemical detection of human papillomavirus DNA type 16 using a pyrrolidinyl peptide nucleic acid probe immobilized on screen-printed carbon electrodes," Biosensors and Bioelectronics, vol. 54, pp. 428-434, 2014.

[17] G. Jo, M. Choe, S. Lee, W. Park, Y. H. Kahng, and T. Lee, “The application of graphene as electrodes in electrical and optical devices," Nanotechnology, vol. 23, no. 11, Article ID 112001, 2012.

[18] K.-Y. Shin, J.-Y. Hong, and J. Jang, "Micropatterning of graphene sheets by inkjet printing and its wideband dipoleantenna application," Advanced Materials, vol. 23, no. 18, pp. 2113-2118, 2011.

[19] Y.-M. Wu, X. Lv, B. K. Tay, and H. Wang, "Carbon nanotubebased printed antenna for conformal applications," in Proceedings of the International Conference on Optoelectronics and Microelectronics (ICOM '13), pp. 91-93, Harbin, China, September 2013.

[20] K. Jost, D. Stenger, C. R. Perez et al., "Knitted and screen printed carbon-fiber supercapacitors for applications in wearable electronics," Energy \& Environmental Science, vol. 6, no. 9, pp. 2698$2705,2013$.

[21] M. H. Ervin, L. T. Le, and W. Y. Lee, "Inkjet-printed flexible graphene-based supercapacitor," Electrochimica Acta, vol. 147, pp. 610-616, 2014.

[22] Y. Xu, M. G. Schwab, A. J. Strudwick et al., "Screen-printable thin film supercapacitor device utilizing graphene/polyaniline inks," Advanced Energy Materials, vol. 3, no. 8, pp. 1035-1040, 2013.

[23] D. W. Zhang, X. D. Li, H. B. Li et al., "Graphene-based counter electrode for dye-sensitized solar cells," Carbon, vol. 49, no. 15, pp. 5382-5388, 2011. 
[24] L. Kavan, J.-H. Yum, and M. Grätzel, “Graphene nanoplatelets outperforming platinum as the electrocatalyst in co-bipyridinemediated dye-sensitized solar cells," Nano Letters, vol. 11, no. 12, pp. 5501-5506, 2011.

[25] P. C. Bouten, P. J. Slikkerveer, and Y. Leterrier, "Mechanics of ITO on plastic substrates for flexible displays," Flat Panel Displays, 2005.

[26] M. Nasr Saleh and G. Lubineau, "Understanding the mechanisms that change the conductivity of damaged ITO-coated polymeric films: a micro-mechanical investigation," Solar Energy Materials and Solar Cells, vol. 130, pp. 199-207, 2014.

[27] T. Ando, "The electronic properties of graphene and carbon nanotubes," NPG Asia Materials, vol. 1, no. 1, pp. 17-21, 2009.

[28] J.-P. Salvetat, J.-M. Bonard, N. B. Thomson et al., "Mechanical properties of carbon nanotubes," Applied Physics A: Materials Science and Processing, vol. 69, no. 3, pp. 255-260, 1999.

[29] I. W. Frank, D. M. Tanenbaum, A. M. Van der Zande, and P. L. McEuen, "Mechanical properties of suspended graphene sheets," Journal of Vacuum Science \& Technology B: Microelectronics and Nanometer Structures, vol. 25, no. 6, pp. 2558-2561, 2007.

[30] G. Wróblewskia, M. Słomaa, D. Janczak, A. Młozniakb, and M. Jakubowska, "Influence of carbon nanoparticles morphology on physical properties of polymer composites," Acta Physica Polonica A, vol. 125, no. 4, pp. 861-863, 2014.

[31] L. Qiu, X. Yang, X. Gou et al., "Dispersing carbon nanotubes with graphene oxide in water and synergistic effects between graphene derivatives," Chemistry, vol. 16, no. 35, pp. 1065310658, 2010.

[32] L. David, A. Feldman, E. Mansfield, J. Lehman, and G. Singh, "Evaluating the thermal damage resistance of graphene/carbon nanotube hybrid composite coatings," Scientific Reports, vol. 4, article 4311, 2014.

[33] D. R. Dreyer, S. Park, C. W. Bielawski, and R. S. Ruoff, "The chemistry of graphene oxide," Chemical Society Reviews, vol. 39, no. 1, pp. 228-240, 2010.

[34] C. Punckt, F. Muckel, S. Wolff et al., "The effect of degree of reduction on the electrical properties of functionalized graphene sheets," Applied Physics Letters, vol. 102, no. 2, Article ID 023114, 2013.

[35] P. Han, Y. Yue, Z. Liu et al., "Graphene oxide nanosheets/multiwalled carbon nanotubes hybrid as an excellent electrocatalytic material towards $\mathrm{VO}^{2+} / \mathrm{VO}_{2}^{+}$redox couples for vanadium redox flow batteries," Energy \& Environmental Science, vol. 4, no. 11, pp. 4710-4717, 2011.

[36] W. S. Jang, S. S. Chae, S. J. Lee, K. M. Song, and H. K. Baik, "Improved electrical conductivity of a non-covalently dispersed graphene-carbon nanotube film by chemical p-type doping," Carbon, vol. 50, no. 3, pp. 943-951, 2012.

[37] K. L. Lu, R. M. Lago, Y. K. Chen, M. L. H. Green, P. J. F. Harris, and S. C. Tsang, "Mechanical damage of carbon nanotubes by ultrasound," Carbon, vol. 34, no. 6, pp. 814-816, 1996.

[38] A. Lefebvre, Atomization and Sprays, CRC Press, New York, NY, USA, 1988.

[39] G. Haacke, "New figure of merit for transparent conductors," Journal of Applied Physics, vol. 47, no. 9, pp. 4086-4089, 1976.

[40] F. Abelès, "VI methods for determining optical parameters of thin films," Progress in Optics, vol. 2, pp. 249-288, 1963.

[41] M. Born and E. Wolf, Principles of Optics: Electromagnetic Theory of Propagation, Interference and Diffraction of Light, Cambridge University Press, 1999.
[42] L. Hu, D. S. Hecht, and G. Grüner, "Infrared transparent carbon nanotube thin films," Applied Physics Letters, vol. 94, no. 8, Article ID 081103, 2009. 

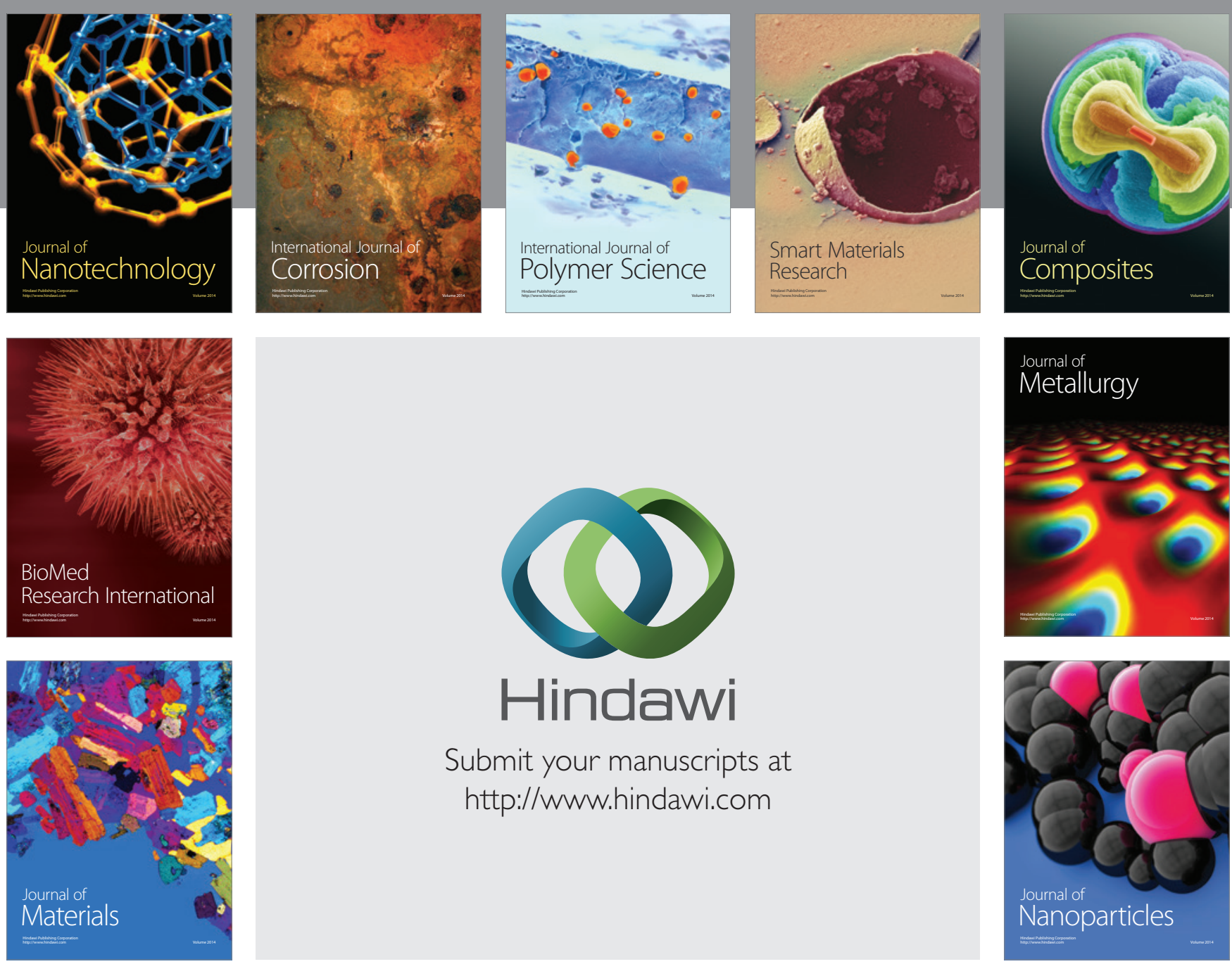

Submit your manuscripts at http://www.hindawi.com
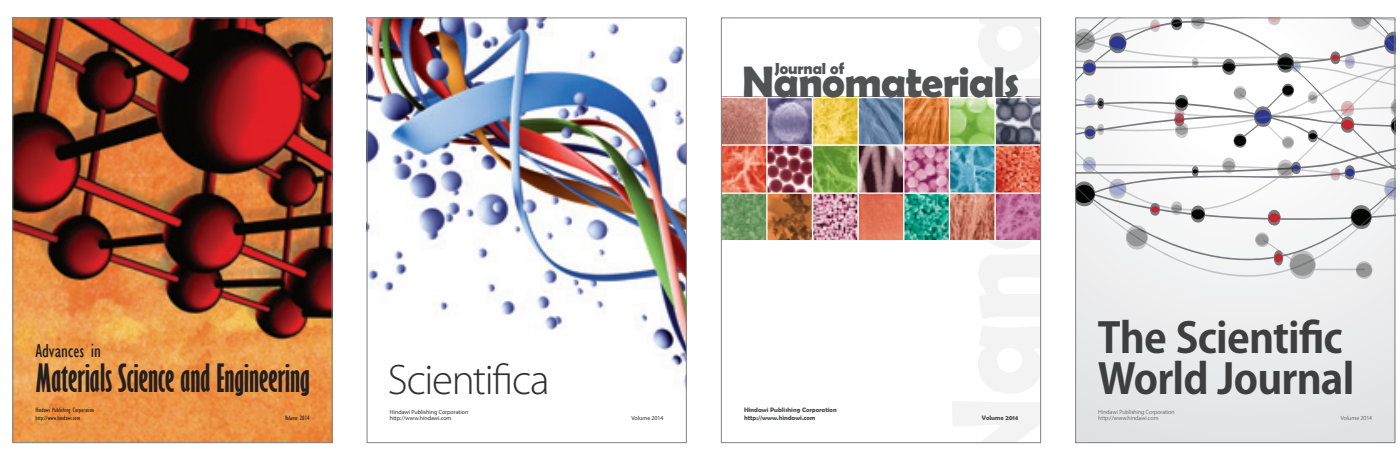

\section{The Scientific World Journal}
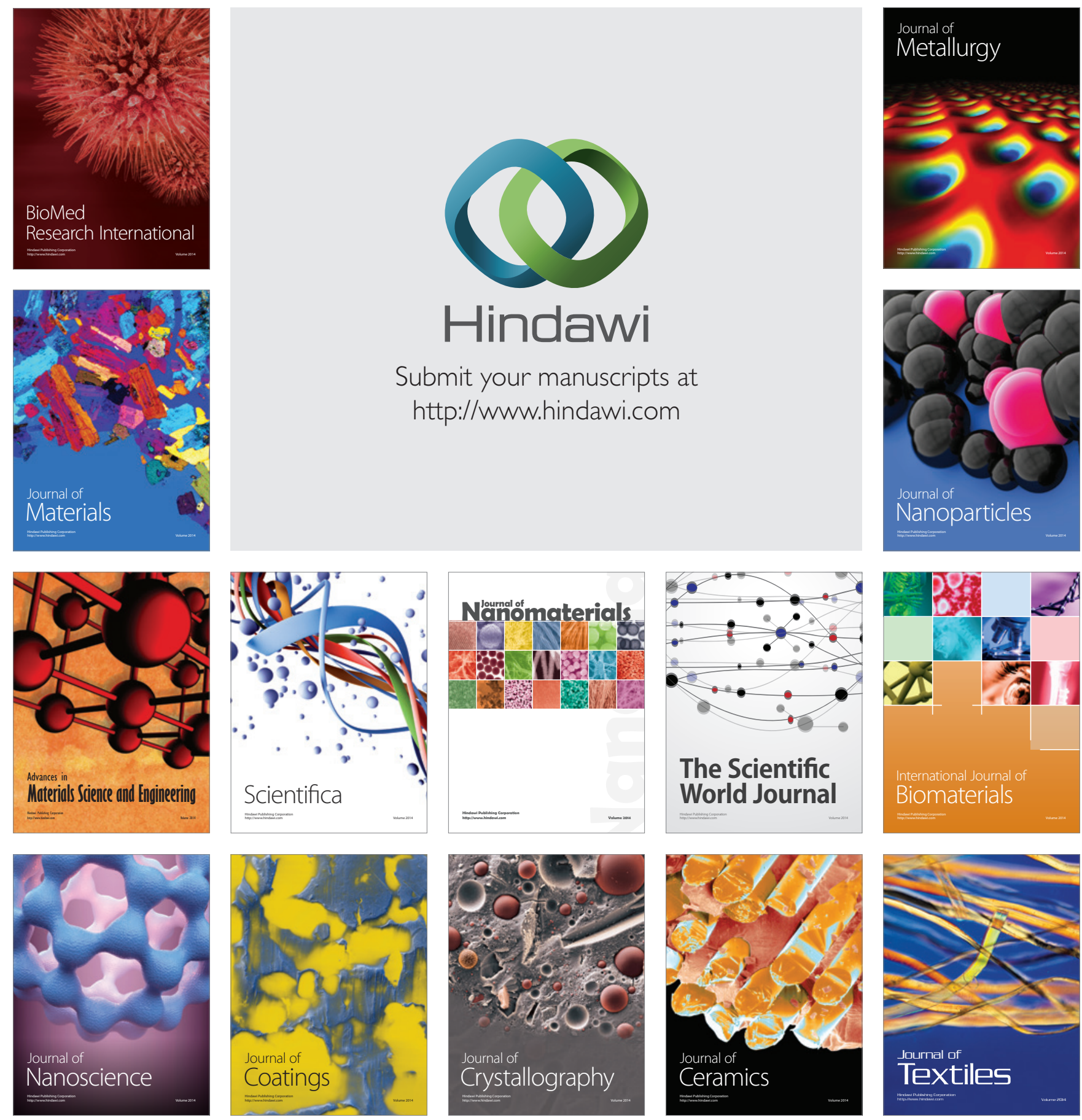